\title{
Educating Part-Time MBAs For The Global Business Environment
}

\author{
W. Alan Randolph, University Of Baltimore, USA
}

\begin{abstract}
To be successful managers in the business world of the $21^{\text {st }}$ century, MBA students must acquire global skills of business acumen, reflection, cultural sensitivity, and multi-cultural teamwork. Developing these skills requires international experience, but educating part-time MBAs creates a special challenge demanding both rigor and efficiency. This paper describes an innovative way to address this challenge. Based on the study tour concept, the course incorporates a three-part multinational opportunity analysis project for a full semester, and provides students a chance to interact with professors and students from a university in another country. The students develop critical global skills with only an abbreviated travel experience abroad.
\end{abstract}

Keywords: Global business education, Global business skills, Study abroad experiences

\section{INTRODUCTION}

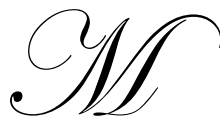

BAs who aspire to manage successfully in the $21^{\text {st }}$ century must understand the complex and dynamic global business environment in which they will operate (Friedman, 2005; Laughton, 2005; Jeannet, 2000, Ch. 1). Technological advances continue to shrink the world, providing both global opportunities and challenges for businesses. When markets tap out in domestic locales, the world can offer new markets with ever-expanding potential. At the same time, the doors to one's local markets are wide open for foreign competition. And as production options expand to include world wide access to cheaper and often better quality markets, businesses are faced with a wide variety of production options. The business model of the $21^{\text {st }}$ century has moved from domestic to multi-national to global, and in many cases to transnational. The challenge for managers to succeed in this environment has grown exponentially.

\section{THE CHALLENGE FOR MANAGERS}

No longer is it enough to be able to manage partnership, subsidiary, and joint venture operations in other countries while sitting in the home country or occasionally traveling abroad (Meier, 1998, Ch. 1; Voris, 1997)). Today's global managers must understand the intricacies of diverse and changing international markets for their company's various products and/or services. Is there a market for their products and/or services in other countries? How must they adapt the products and/or services for varying markets around the world? Today's global managers must also understand the complexities of international finance, including exchange rate fluctuations (such as has occurred with the US dollar to Euro exchange in recent years), economic cycles around the world (sometimes including economic collapse as happened recently in Argentina), and international flows of capital. Indeed, it helps to understand the dynamics of privatization economics that is occurring in such wide spread countries as Poland and China. Plus, it is essential to understand the many ways in which countries are governed and the politics and laws that are encountered in a wide variety of countries. Enhanced communications, technology, and transportation, plus an ever increasingly globalized work force and customer base have created a complex, dynamic, and challenging world for business operations in the $21^{\text {st }}$ century.

Today managers must be able to manage cross-nationally as they work with people from multiple cultures to serve multiple business settings, using products and services that cut across borders and cultures that are different and often conflicting (Saee, 2007; Jeannet, 2000, Ch. 2). Indeed, managers must be able to manage cross-national 
issues even if they themselves never leave their home country. Companies today are looking for managers who have intense passion about their work, who exhibit energetic initiative, who have learned cultural sensitivity, and who see the world as their base of operation (Green, Hassen, Immelt, Marks, \& Meiland, 2003). Where ever one may manage, the growing diversity of the multi-national workforce demands a sensitivity and flexibility to global issues that few managers are born with, nor have they typically developed these skills through their academic experience. The challenge facing management education has also grown exponentially.

\section{THE CHALLENGE FOR MANAGEMENT EDUCATION}

Management education has for years been the domain of the MBA program. Increasing numbers of people pursue and receive their MBA from a wide variety of business schools, with the primary model for the MBA coming from North America. True, there are a growing number of MBA programs in Europe, Asia, South America, and even Africa, but the model of education remains focused on business functions, and that model was developed in North America (Mintzberg \& Gosling, 2002). While there has been a growing emphasis on the international elements of a business education, far too many MBA programs provide only a course or two and a cursory treatment of the challenge of conducting business in the global market place. Adding a few international cases to a curriculum and an overview course on international business simply does not prepare a manager adequately (Han, 2004).

To function in a transnational workplace requires managers to learn both a broad perspective on multicultural people, situations, and practices, as well as an understanding of the interdependence of political, economic, marketing and financial risks. Managers must learn how events around the globe are linked in a variety of fast acting ways. The economic crisis in Argentina very quickly affected the entire Latin American region, and just a quickly negatively impacted the economy in the United States. More recently, conflict over the handling of a war in Iraq has impacted relationships and trade activities between Europe and the United States, and has even impacted efforts to deal with disease and economic development in Africa.

The world is a highly interconnected place in the $21^{\text {st }}$ century, and managers must learn to understand the gestalt that is our world today. Today's managers must also have the ability to learn about and work within a variety of national economies and cultures that are quite different from each other as well as from the manager's home culture. At the same time, a manager must acquire the ability to gain a specific understanding of each culture within which the manager may be working at any given point in time. In other words, avoiding great difficulties (even failure) in today's global workplace requires one to have an understanding of multiple cultures as well as the ability to develop an in-depth understanding of any one culture at a time (Schneider \& Barsouxl, 2003, Chs. 1-3). By far, the best way to learn these skills is to spend time living and studying abroad for extended periods of time (at least a few months in each new culture), and to study and/or work abroad in multiple cultures. In this way, one not only learns about several different cultures but also acquires the discipline of how to learn about cultures. To become a transnational manager, it is not enough to know about one culture in depth; a transnational manager must have the skill to diagnose and adapt to a variety of cultures, often on a minute's notice.

Unfortunately, the challenge facing MBAs studying study to improve their skills is one of insufficient time to learn other cultures while also learning the myriad of other skills needed to succeed in today's business environment. Consider, for example, the challenge facing a typical MBA student, who must learn the skills of international business and dealing with multiple cultures, while also learning the functions of accounting, marketing, finance, economics, MIS, and the skills of teamwork, diversity, communication, ethics, leadership, etc. Now consider how difficult preparation for this challenge is if one is facing it as a part-time MBA student who works full time, has a family, and attends school at night or on weekends to earn the degree. Time is precious, so the challenge shifts from having enough time to acquire the skills to having experiences that provide a profound impact in a short period of time. The skills must be learned but in less time and with greater efficiency. In the mid 1990s, when we began to focus on preparing our MBA students at the University of Baltimore for the transnational challenge, we wondered if it was even possible to do the job effectively for part- time MBA students. 


\section{UNIQUE CHALLENGE, POWERFUL ANSWER}

Since part-time MBA students cannot afford the time to spend even several weeks abroad, the longhonored tradition of the "semester abroad experience" is just not possible for part-time students. Still, we know that they must learn to operate in a multinational world if they are to become successful managers. How can we address this unique challenge? Certainly, we could offer them courses on national cultures and models for understanding cultural differences (e.g. Hofstede, 1997). We could have them analyze multinational cases and interact with international students who are attending their university. For example, at the University of Baltimore approximately $20 \%$ of the MBA students come from Turkey, Thailand, China, Latin America, Kenya, Ghana, Germany and other countries, thus providing a rich multicultural experience just from being in class together. Indeed, the coupling of this mixture of students with the pedagogy of group projects, case discussion, and experiential exercises provides a wonderful learning opportunity for addressing the global challenge facing MBAs today. But is this inter-cultural experience enough to prepare these students for the global business world?

We think not! Part-time MBA students, like full-time MBAs need to learn from the experience of travelling to at least one other country. Our challenge as faculty members for part-time MBAs was to create a powerful learning experience that can occur in a relatively short period of time. Hence, our initial analysis led to the consideration of short, study tour courses that have long been available in business schools. These tour courses include three phases - (1) pre-departure preparation, (2) an in-country experience with business presentations, and (3) a post-trip chance to finalize the learning (Porth, 1997). Unfortunately in analyzing the typical study tour experience in a wide variety of MBA programs, we felt that too many of these tours provide a valuable cultural experience but lack the opportunity to analyze and be responsive to real business issues. We believe such an opportunity for learning is essential for MBA students (part- time or full-time). After consideration of many options, my colleagues and I decided to design a semester long course that would allow time for a thorough business analysis of the global potential of industries in the home market, coupled with a similar in-depth business opportunity analysis of one market abroad. In our analysis of study tours offered by over 40 schools, we did not find even one school that offered this dual local and foreign analysis assignment to MBA students.

In our opinion, this is one of the unique and powerful elements in our International Business Strategy course that we designed specifically to fit the needs of our part-time MBAs. The specific project focus integrating analyses from two countries is a very powerful learning experience. It requires the students to use their business knowledge and multicultural models while actually completing a business opportunity analysis project, much like a manager might conduct to decide about expanding into another country. And on top of all this, by working with another university in the other country to host our visit, we allow the students to hear from local professors, to interact with local students, and to visit businesses in the other country, all with the goal of conducting their analysis of industries with global potential in the other country. As one student who traveled to Berlin noted, "The trip was a life changing experience for me. Also, the lectures by professors from the host university helped me understand Germany's economic situation and leading industries. What we learned from them and from our visits with an investment agency and several businesses helped us in completing our business analysis project." In the following pages we will explain how the course is organized in three parts.

\section{Part One - Analysis Of The Baltimore Region}

Part 1 of the semester-long course (15 weeks) starts with using cases from the text, Transnational Management, by Bartlett, Ghoshal and Beamish (2008) used as the primary means of exposing students to the challenges faced by transnational managers. We also teach the students models for business analysis, including the Porter Diamond Model (Porter, 1990, Ch. 3), and for understanding cultures around the world (we use Hofstede, 1997). During this phase students, working in teams, begin the three-part business opportunity analysis project. Using the Porter Diamond Model (1990, Ch. 3) as a method for analyzing the Baltimore region for its international potential, the students analyze 2-3 industries in the region. Per the Porter Diamond Model, they analyze: (1) Factor Conditions that collectively give the region a competitive advantage in providing a product or service, (2) Demand Characteristics from customers that push the organizations to innovate, (3) Related and Supporting Industries that provide a critical mass of strength that provides advantages over other regions, and (4) Strategy and Structure that 
define local competitive and strategic forces that hone the skills of the local industry for the global environment. From this local analysis, the student teams determine which industries in the Baltimore region have international growth potential. They prepare both written and oral presentations of their analysis and provide a direction for the other two parts of the analysis to follow. The first report provides the initial analysis for Parts II and III of the Final Report (see Appendix A for a description of the assignment).

In working on this first part of the analysis, the students are developing both their "analytic mindset" and their "collaborative mindset" (Mintzberg \& Gosling, 2002). They also learn some very useful information about the strengths and weaknesses that the Baltimore region has relative to a global business environment. In addition, during this phase of the course, the students have a chance to apply concepts from many of their other MBA courses, such as, economics, marketing, and finance to an analysis of the international potential for Baltimore. Furthermore, since our classes tend to include students from a variety of countries, this team project begins to offer students the chance to focus on their "reflective mindset" (Mintzberg \& Gosling, 2002); classmates from a variety of countries may not have the same expectations about project work, deadlines, and professionalism. Learning to work effectively in these multicultural teams provides many opportunities for students to learn about themselves and to learn to understand to work with people from rather different cultural backgrounds. Just imagine a team comprised of two US students, a Turkish student, a Kenyan student, and a Korean student analyzing the business potential of Baltimore and preparing written and oral reports of their analysis. The potential for reflective learning is immense.

\section{Part Two - Analysis Of A Foreign Location}

Part 2 of the course ensues as the student teams begin an analysis of another region of the world, again using the Porter Diamond Model (Porter, 1990, Ch. 3) but also using a cultural comparison of Baltimore with the other region. Over the years, we have provided students the chance to analyze and travel to such places as Rennes, France; Krakow, Poland; Lima, Peru: and Berlin, Germany). The student teams analyze the region relative to the four elements of the Porter Diamond Model and determine strengths and weaknesses relative to a global business environment. In addition, they learn about the culture of the region drawing first upon the Hofstede (1997) cultural dimensions and then other elements of cultural difference (such as, time orientation, spatial impact, low/high context, religious impact, etc.). They also explore legal, political and economic factors that affect business in the region and affect the region's international business potential.

It is during this second part of the course that the students are afforded the opportunity to travel to the other country to study, first hand, the international business potential of the region. Armed with their pre-travel Porter Diamond Model analysis and the cultural analysis conducted from the United States, the students focus energy for 10 days on site in the other country expanding and deepening their analysis. To assist them in their work, students are lead by a University of Baltimore professor and hosted by a local university. Our students attend lectures offered by professors at the local university on such topics as international economics, cultural dimensions of the country, and entrepreneurship in the country. For example, the students have had very interesting and informative presentations of Privatization Economics in both Poland and Peru, providing them an appreciation of the risks involved in business ventures in developing economies. The students also are afforded the chance to meet and interact with students from the host university, as they informally and socially learn more about working with people from another culture, all the while staying focused on the goal of a thorough business analysis of the region.

The local university also arranges visits with local business development agencies and both US and local businesses. During these visits the students learn first hand about the issues of conducting business in the other country and they can ask questions to gain additional insight relative to their opportunity analysis project. Finally, the local university also organizes visits to cultural sites so the students can learn about the culture and history of the region. For example, in Krakow, Poland, we have visited the Wavel Castle to learn about the glory days of Poland. We also visit the Jewish ghetto from which nearly 500,000 people were sent to the concentration camp at Auschwitz (which we also visit). Such experiences provide a depth and perspective to the industry analysis the students are conducting. 
As one can imagine, these 10-day experiences are intense, exhilarating, and exhausting (some students feel they cannot afford to lose time sleeping during the trip). The trips with the project focus on top of mind allow a wonderful opportunity for students to develop their "worldly mindset" (Mintzberg \& Gosling, 2002). They are immersed in the other culture, but not just as tourists. They have work to do and must navigate the cultural differences to do so. This experience also continues the development of their "reflective mindset," as they now learn from actual experience to see the US and themselves from an outsider's perspective. There can be nothing quite so insightful as discussing US politics and policy over a drink with students from another country. Furthermore, habits, practices, and travel experience vary widely among the students who make the trips, but they learn to know and depend on each other in a variety of ways during their time abroad. The result is enhanced development of their "collaborative mindset" (Mintzberg \& Gosling, 2002).

Upon returning to Baltimore, the student teams complete their analysis of the region and prepare written and oral reports focusing on their analysis of the global potential of the other region. The report provides the initial analysis for Parts IV, V and VI of the Final Report (see Appendix A).

\section{Part Three - Proposing A New Business Venture}

Part 3 of the course and the final part of the project occurs back in Baltimore and requires the student teams to reflect on the analyses of Baltimore and the other region in the world and the industries with global potential. At this point of the project, students must move from an analysis frame of mind that was so valuable in Parts 1 and 2 to a conceptual, thinking mindset, what Mintzberg \& Gosling (2002) might refer to as "the action mindset." Here our students face the challenge of shifting from collecting and analyzing information about Baltimore and the other region of the world to utilizing the information to make recommendations about what plan of action could be followed relative to a business venture between Baltimore and the other country. They must step back and think about what they have learned about Baltimore and the other country from their analysis of the Porter Diamond dimensions of industries and the cultural understanding of both settings. On the basis of this diagnosis, they must look into the future and propose a viable business venture. They must make recommendations about joint ventures or business partnerships to exploit the potential business opportunities between Baltimore and the other country.

The final report follows a prescribed format (see Appendix A - all parts), and information from the first two reports are refined and integrated into this final report as Parts II through VI. Part VII is the key focus of this Final Report, and we often find that this section is the most taxing for our students. They are excellent at finding and reporting on information, but their conceptual skills are often not as strong. The result is that they learn a great deal from the exercise of preparing this final report. Once the written report is completed, the oral report is given. These presentations are the culmination of a great deal of work and are always a high point of the semester. Usually, some local business people are invited, and they are often amazed at the quality of the analyses and proposals for business ventures involving Baltimore and the other region of the world.

\section{POWERFUL LEARNING EXPERIENCE}

The primary goal of the International Business Strategy course is to provide our part-time MBA students with the opportunity to work in teams on a real world, multi-national project that requires a business and cultural analysis of Baltimore and another region of the world. The combination of a rigorous opportunity analysis of the global potential of Baltimore businesses prior to going abroad coupled with a similar analysis of another region and the chance to travel to the other country provides a powerful learning experience for our part-time MBA students. The Final Report extends this learning beyond data analysis and international experience to the creative work of proposing a viable business venture between Baltimore and the other region.

Since 1995, we have conducted this course with multiple trips to Rennes, France; Krakow, Poland; Lima, Peru; and Berlin, Germany. In every case, the trip has been a high point for all students who have made the trips. For example, One student who traveled to France said, "This course provided me with my most meaningful experience in the MBA program." 
If we step back from our experiences in teaching this course and reflect on what students learn, it is clear that they gain knowledge in all of the mindsets from Mintzberg \& Gosling (2002): reflective, analytic, worldly, collaborative, and action. From the eclectic and intense experience of working on the business opportunity analysis project, prior to, during, and after the trip, students are presented with an integrative learning experience that allows for synergistic learning in all five mindsets. The three-part project assignment is the key; it provides focus and an accountability that makes the learning essential and that drives the intensity of the experience while abroad. Then too, having a host university to provide both intellectual content and inter-cultural experiences with businesses, cultural sites and their students is a definite asset for the experience during the travel portion of the course.

During the preparation for travel and during the experiences abroad, students are provided the opportunity to learn relative to their reflective and worldly mindsets. Their experience offers both a cultural mirror for selfintrospection, as well as a window into another part of the world. They gain a reverse perspective on the US, as seen from the outside, while also dealing with ethical, legal, political and logistical issues abroad. One simple but rather challenging experience that occurred in 1999 during our first trip to Krakow, Poland, highlights the opportunity for such learning.

When we arrived into the Warsaw Airport, we were expecting to be met and driven to the train station to get the train for our 3-hour ride to Krakow. Unfortunately, no one was there to meet us, and we could find no one in the airport who spoke English -- needless to say our Polish was not that good either. The immediate reaction of several of the students was a mild case of panic, but the professor and one student, armed with a Polish phrase book, managed to explain to a taxi driver and negotiate a rate to get us to the train station. Upon arriving at the train station, we were thrust into a mass of humanity that caused great concern for stealing our bags and also made it hard to determine where to buy the tickets to Krakow (there were different ticket windows depending on your destination, but all signs were in Polish, of course). Alas, amidst the panic of some of the students, the professor and student with the phrase book managed to locate the proper ticket window and purchase second class tickets to Krakow. Once on the train we relaxed, but upon arriving in Krakow, we again encountered problems -- the person who was to meet us was not at the station. Finally, he did come but with only a small car, necessitating two trips to our lodging, as darkness fell and the cold temperatures surrounded us.

No experience could have been better for introducing the students to business in a developing country. Things just do not work like we think they should, based on our US experiences. And when confronted with problems in a place where you cannot speak or read the language, there is a fabulous opportunity to learn about cultural differences and about oneself. We had numerous discussions during and after that trip about how different students had reacted and what they had learned from that experience, which could have been learned in no other manner (especially not while sitting in a classroom in the US reading a case or watching a video about business in Poland).

The project focus for the course creates opportunities for learning that combines the analytic, collaborative and action mindsets. As the students work in teams on the opportunity analysis project, they must employ project skills to address a results focus with clear outcomes, and they must get the three parts of the project completed by specified deadlines. They must also employ teamwork skills so that communication lines remain open and the sharing of leadership in the team occurs naturally and smoothly as the project is completed. The three parts of the project also build on each other to culminate in the final report. Working on the local analysis, students learn to use the Porter Diamond Model for analysis, and they learn how to collect and report on information relative to that model. Working on the country analysis phase, the students further their understanding of the Porter Diamond Model, while also learning a great deal about cultural analysis. As they work on the final report, they learn to pull it all together and to think beyond the mere analysis of data they can so efficiently collect. As implied previously, this last phase not only is the culmination of the effort from the entire semester. It is also a mind expanding experience because it uses conceptual skills and logic skills on top of analytic skills -- a combination that is essential for working in the global business world 


\section{CONCLUSION}

In conclusion, we can reiterate that while part-time students do not have the luxury of spending extended amounts of time abroad, the innovative design of this three-part project-based course provides the opportunity to gain a 3 month global experience with minimal time abroad. The intensive 10-day experience abroad hosted by a local university provides a valuable inter-cultural experience that is driven by the opportunity analysis assignment. The learning is powerful, real, and emotional for every student who has made the journey with our course. We feel it addresses a real need in a creative and productive fashion. Once part-time students complete this experience, they are better prepared to work in the global arena. As one student who traveled to Poland said, "For students interested in international business, the travel and work on the project was the only way to really learn about the many subtle issues that people confront in international work."

But while we know students learn a great deal from this course, we as faculty can learn perhaps even more in providing them with this learning experience. Educating MBAs for the global business environment means educating ourselves as professors about how to address a complex and dynamic challenge. Educating part-time students only intensifies things. Perhaps the design of this course can help faculties of other part-time students move closer to meeting that challenge. I believe it has for the faculty and students of the University of Baltimore.

W. Alan Randolph is Professor of International Business and Director, Center for Global Business Studies, Merrick School of Business, University of Baltimore, Maryland. His graduate International Business courses help students gain real experience by traveling abroad for analysis projects to places like China, Brazil, Poland, Peru, Germany. Alan's research focuses on Cultures of Empowerment, Global Leadership, and International Business Challenges. His books are popular around the world. Recent books: GO TEAM! Take Your Team to the Next Level and Empowerment Takes More Than A Minute. Alan holds a Bachelors of Industrial Engineering degree, Georgia Institute of Technology and Masters and Ph.D. degrees in Business Administration, University of Massachusetts.

\section{REFERENCES}

1. Bartlett, C. A., Ghoshal, S. \& Beamish, P. 2008. Transnational management: Text, cases and readings in cross-border management, 5th. ed.). New York: The McGraw Hill Companies, Inc.

2. Friedman, T. L. 2005. The world is flat: A brief history of the twenty-first century. New York: Farrar, Straus and Giroux.

3. Green, S., Hassan, F., Immelt, J., Marks, M., \& Meiland, D. 2003. In search of global leaders. Harvard Business Review, 81: 38-45.

4. Han, P. 2004. The international dimensions of functional courses. American Business Review, 22(1) 56-66.

5. Hofstede, G. 1997. Culture and organizations: Software of the mind. New York: The McGraw Hill Companies, Inc.

6. Jeannet, J. P. 2000. Managing with a global mindset. London: Pearson Education Limited.

7. Laughton, D. 2005. The development of international business as an academic discipline: Some implications for teachers and students. Journal of Teaching in International Business, 16(3): 47-59.

8. Meier, G. M. 1998. The international environment of business: Competition and governance in the global economy. New York: Oxford University Press, Inc.

9. Mintzberg, H. \& Gosling, J. 2002. Educating managers beyond borders. Academy of Management Learning and Education, 1:64-76.

10. Porter, M. E. 1990. The competitive advantage of nations. Chapter 3: 69-130. New York: The Free Press.

11. Porth, S. 1997. Management education goes international: A model for designing and teaching a study tour course. Journal of Management Education, 21: 190-199.

12. Saee, J. 2007. Intercultural awareness is the key to international business success. The EFMD Business Magazine, 1(3): 56-59.

13. Schneider, S. C. \& Barsoux, J. L. 2003. Managing across cultures ( $2^{\text {nd }}$ ed.). Part 1. London: Pearson Education Limited.

14. Voris, W. 1997. A retrospective of international business education in the United States over the past fifty years. The International Executive, 39(2): 271-282. 


\section{APPENDIX A}

Final Report

MGMT 781 - International Business Strategy

This written and oral report should focus on both the Baltimore region of the United States and the other country you chose. It should include an analysis of both regions based on the Porter Diamond Model, a description of selected industries in each country, a cross-cultural analysis (as in the report on your country of choice), and recommendations for potential joint venture or other international opportunities. The report should not exceed 20 word processed pages (figures and bibliography not counted), and you should prepare a Power Point presentation that does not exceed 40 minutes, including at least 5 minutes for questions and answers.

The report should be divided into seven sections as follows:

I. One-page Executive Summary of the Report

II. Analysis of the Baltimore region using the Porter Diamond Model

A. Analysis of each of the four determinants of competitive advantage (factor conditions, demand conditions, related and supporting industries, and firm strategy, structure and rivalry)

B. Suggested industries for opportunity analysis

III. Descriptions of 2-3 Baltimore industries for potential global expansion
A. History of industries
B. Current market and economic conditions
C. Key competitors
D. Industry strengths and weaknesses

IV. Analysis of country/region of choice using the Porter Diamond Model

A. Analysis of each of the four determinants of competitive advantage (factor conditions, demand conditions, related and supporting industries, and firm strategy, structure and rivalry)

B. Suggested industries for opportunity analysis

V. Descriptions of 2-3 industries in the country for potential global expansion

A. History of industries

B. Current market and economic conditions

C. Key competitors

D. Industry strengths and weaknesses

VI. Analysis of cultural aspects of the country/region of choice
A. Describe the cultural dimensions of this country/region (for example, draw upon the Hofstede dimensions of Power Distance, Uncertainty Avoidance, Individualism, and Masculinity)
B. Compare the country/region to the Baltimore region
C. What problems might arise from the differences?
D. What synergies might arise from the differences?

VII. Recommendations for New Business
A. What are your recommendations for potential business opportunities between Baltimore and the other country?
B. What specific industries offer the best potential? Are there specific companies to suggest?
C. What is the scope of the potential business venture?
D. What do you see as the potential payoff? What are the main risks to the venture? 